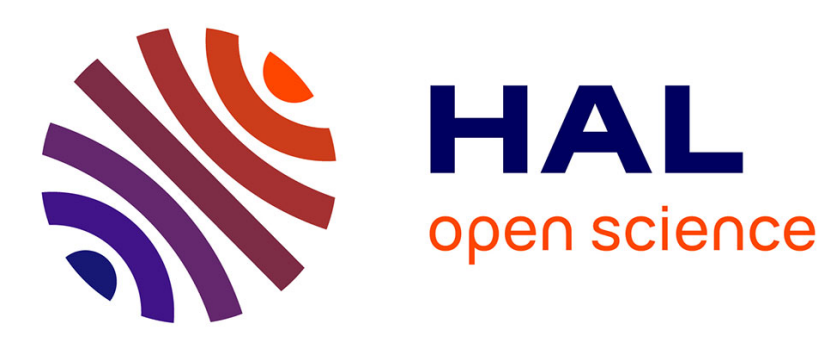

\title{
Efficiency of immersion mode ice nucleation on surrogates of mineral dust
}

\author{
C. Marcolli, S. Gedamke, T. Peter, B. Zobrist
}

\section{To cite this version:}

C. Marcolli, S. Gedamke, T. Peter, B. Zobrist. Efficiency of immersion mode ice nucleation on surrogates of mineral dust. Atmospheric Chemistry and Physics, 2007, 7 (19), pp.5081-5091. hal-00296346

\section{HAL Id: hal-00296346 \\ https://hal.science/hal-00296346}

Submitted on 4 Oct 2007

HAL is a multi-disciplinary open access archive for the deposit and dissemination of scientific research documents, whether they are published or not. The documents may come from teaching and research institutions in France or abroad, or from public or private research centers.
L'archive ouverte pluridisciplinaire HAL, est destinée au dépôt et à la diffusion de documents scientifiques de niveau recherche, publiés ou non, émanant des établissements d'enseignement et de recherche français ou étrangers, des laboratoires publics ou privés. 


\title{
Efficiency of immersion mode ice nucleation on surrogates of mineral dust
}

\author{
C. Marcolli, S. Gedamke, T. Peter, and B. Zobrist \\ Institute for Atmospheric and Climate Science, ETH Zurich, Switzerland \\ Received: 26 June 2007 - Published in Atmos. Chem. Phys. Discuss.: 4 July 2007 \\ Revised: 21 September 2007 - Accepted: 24 September 2007 - Published: 4 October 2007
}

\begin{abstract}
A differential scanning calorimeter (DSC) was used to explore heterogeneous ice nucleation of emulsified aqueous suspensions of two Arizona test dust (ATD) samples with particle diameters of nominally $0-3$ and $0-7 \mu \mathrm{m}$, respectively. Aqueous suspensions with ATD concentrations of $0.01-20 \mathrm{wt} \%$ have been investigated. The DSC thermograms exhibit a homogeneous and a heterogeneous freezing peak whose intensity ratios vary with the ATD concentration in the aqueous suspensions. Homogeneous freezing temperatures are in good agreement with recent measurements by other techniques. Depending on ATD concentration, heterogeneous ice nucleation occurred at temperatures as high as $256 \mathrm{~K}$ or down to the onset of homogeneous ice nucleation $(237 \mathrm{~K})$. For ATD-induced ice formation Classical Nucleation Theory (CNT) offers a suitable framework to parameterize nucleation rates as a function of temperature, experimentally determined ATD size, and emulsion droplet volume distributions. The latter two quantities serve to estimate the total heterogeneous surface area present in a droplet, whereas the suitability of an individual heterogeneous site to trigger nucleation is described by the compatibility function (or contact angle) in CNT. The intensity ratio of homogeneous to heterogeneous freezing peaks is in good agreement with the assumption that the ATD particles are randomly distributed amongst the emulsion droplets. The observed dependence of the heterogeneous freezing temperatures on ATD concentrations cannot be described by assuming a constant contact angle for all ATD particles, but requires the ice nucleation efficiency of ATD particles to be (log)normally distributed amongst the particles. Best quantitative agreement is reached when explicitly assuming that high-compatibility sites are rare and that therefore larger particles have on average more and better active sites than smaller ones. This analysis suggests that a particle has to have a diameter of at least $0.1 \mu \mathrm{m}$ to exhibit on average one active site.
\end{abstract}

Correspondence to: C. Marcolli

(claudia.marcolli@env.ethz.ch)

\section{Introduction}

Ice crystals in the atmosphere may form spontaneously by homogeneous nucleation of cloud droplets and aqueous aerosol particles or triggered by heterogeneous nucleation on surfaces of so-called ice nuclei (IN). Field measurements show that ice formation in cumuli- and stratiform clouds begins at temperatures much warmer than those associated with homogeneous ice nucleation in pure water (e.g. Hobbs and Rangno, 1985; Baker, 1997). Therefore, the partial glaciation of these clouds is ascribed to heterogeneous ice nucleation that may occur when insoluble particles come in contact with (contact freezing), are immersed in (immersion freezing) or act as cloud condensation nuclei for (condensation freezing) water droplets (Pruppacher and Klett, 1997). Cloud droplet freezing on heterogeneous ice nuclei has been confirmed by the chemical identification of aerosol particles found in the center of ice crystals. These particles are often composed of insoluble material such as fly ash, kaolinite, montmorillonite or further minerals (Kumai, 1961; Kumai and Francis, 1962; DeMott et al., 2003a), and may originate from large desert regions such as the Sahara (DeMott et al., 2003b; Sassen et al., 2003).

Mineral surfaces are known to effectively initiate ice formation. Water droplets of kaolinite and montmorillonite suspensions were observed to freeze between $-14^{\circ}$ and $-30^{\circ} \mathrm{C}$, and even higher temperatures are reported when the same nuclei induced freezing in the contact mode (Pitter and Pruppacher, 1973). However, in these measurements the concentration of the IN and consequently also the active surface was not quantified. Hung et al. (2003) found that the heterogeneous ice nucleation rates of ammonium sulfate solution droplets with a mineral dust core depend, beside temperature and ice supersaturation, on the size of the immersed mineral particle. Size-dependent ice nucleation efficiencies of different mineral dusts were also found when a supersaturated water vapor directly crystallized onto a solid surface (deposition mode; Archuleta et al., 2005). The present study goes beyond the work by Hung et al. (2003) and Archuleta

Published by Copernicus Publications on behalf of the European Geosciences Union. 
et al. (2005) by providing a comprehensive description of the nucleation process and by quantitatively explaining the thermograms in terms of an active-site-based model of heterogeneous nucleation.

In the derivation of a heterogeneous nucleation rate from an experimental dataset generally the stochastic hypothesis (Pruppacher and Klett, 1997; Vali, 1994; Martin, 2000) is applied, namely, that the ability to nucleate ice (its "activity") per surface area is the same for all IN, either because all IN have identical surface properties or because each aqueous droplet contains a sufficiently large number of IN so that differences in their quality even out. Under these conditions, the nucleation probability can be formulated analogously to the homogeneous case. In contrast, the singular hypothesis (Pruppacher and Klett, 1997; Vali, 1994; Martin, 2000) assumes that the activity of IN varies and that their total number within water droplets is insufficient to ensure statistical homogeneity among the droplets. According to this hypothesis, the freezing temperature of a droplet is determined by that particle in the droplet whose activity is highest. To reproduce cloud formation and precipitation, numerical models need to parameterize heterogeneous ice nucleation taking into account the relevant nucleation modes and ice nuclei. Most models use empirical relations based on the singular hypothesis to parameterize the IN number concentration as functions of temperature and/or ice saturation (e.g. Cotton et al., 1986; Meyers et al., 1992; Diehl and Wurzler, 2004; Lohmann and Diehl, 2006). A further improvement of these models strongly relies on the availability of ice nucleation data that assess the spread of activation thresholds within each single type of IN. To reach this aim, the freezing characteristics of droplets have to be related to the surface area of the immersed IN.

When water-in-oil emulsions are cooled a high number of water droplets nucleate independently from each other and the freezing can be observed via the released latent heat using a differential scanning calorimeter (DSC). This technique has proven successful in measuring homogeneous ice nucleation of water and solution droplets (e.g. Rasmussen and MacKenzie, 1972; Koop et al., 1999; Bertram et al., 2000; Zobrist et al., 2003) as well as heterogeneous nucleation of aqueous suspensions with immersed IN (e.g. Zuberi et al., 2001; Clausse et al., 1991, 2005; Zobrist et al., 2006). These studies usually took the onset of the freezing peak as the ice nucleation temperature. In the present study, we attempt a full analysis of the shape of the freezing curve by taking into account the volume distribution of the water droplets in the emulsions as well as the surface of IN within the droplets and by parameterizing the results in terms of Classical Nucleation Theory (CNT, Pruppacher and Klett, 1997; Zobrist et al., 2007). With such an analysis the spread of IN activity in a sample can be assessed.

We perform this analysis for two different size distributions of Arizona test dusts (ATD). ATD is composed of various mineral species and may serve as surrogate for natu- ral mineral dust particles in the atmosphere, given its composition is similar to that of dusts originating from deserts (Krueger et al., 2005). It has also proven to be a potent IN in the deposition mode (Knopf and Koop, 2006; Möhler et al., 2006).

\section{Experimental}

\subsection{Preparation of emulsions}

The emulsions used in the DSC experiments consist of $80 \mathrm{wt} \%$ of a mixture of lanolin (Fluka Chemical) and mineral oil (Aldrich Chemical) and $20 \mathrm{wt} \%$ of water or an aqueous suspension of Arizona test dust (made with distilled and deionized water, $18.2 \mathrm{M} \Omega$ ). The samples were emulsified by applying a rotor-stator homogenizer (Polytron PT 1300 D with a PT-DA 1307/2EC dispersing aggregate) for $40 \mathrm{~s}$ at 7000 RPM. For homogeneous freezing experiments, two droplet size distributions were investigated:

- "10- $\mu$ m-droplet emulsions": larger droplets with diameters in the range of $2-20 \mu \mathrm{m}$ were obtained with $5 \mathrm{wt} \%$ lanolin in the lanolin/mineral oil mixture,

- "2.4- $\mu$ m-droplet emulsions": smaller droplets with diameters in the range of $0.5-5 \mu \mathrm{m}$ with $23 \mathrm{wt} \%$ lanolin (smaller droplets with higher surface area density require higher emulsifier concentrations).

Approximately $30 \pm 5 \mathrm{mg}$ of the emulsions was used for each DSC measurement. The quality of the emulsions was checked in an optical microscope (Olympus BX 40).

\subsection{Droplet volume distribution of emulsions}

The volume distribution of water droplets in the emulsions was established by analyzing transmitted-light microscope images of emulsion samples prepared on an objective slide. The volume distribution of the emulsion with the smaller water droplets was evaluated by counting the droplets with a bin size of $0.5 \mu \mathrm{m}$ starting from $1 \mu \mathrm{m}$ diameter droplets. The droplet volume distribution of the emulsions with the larger droplets was based on the evaluation of several emulsions with pure and ATD containing water droplets by counting the number of droplets with a bin size of $1 \mu \mathrm{m}$ starting from $2 \mu \mathrm{m}$ diameter. The preparation procedure of the emulsions led to reproducible droplet volume distributions with no dependence on the ATD content. Therefore we used an averaged volume distribution for all emulsions prepared by the same procedure. Figure 1 shows the volume distributions of the two types of emulsions. The emulsions with larger droplets were well fit by a normal distribution with median diameter and variance of $10.0 \mu \mathrm{m}$ and 14.8 , respectively, while the emulsions with smaller droplets corresponded better with a lognormal distribution with median diameter and 


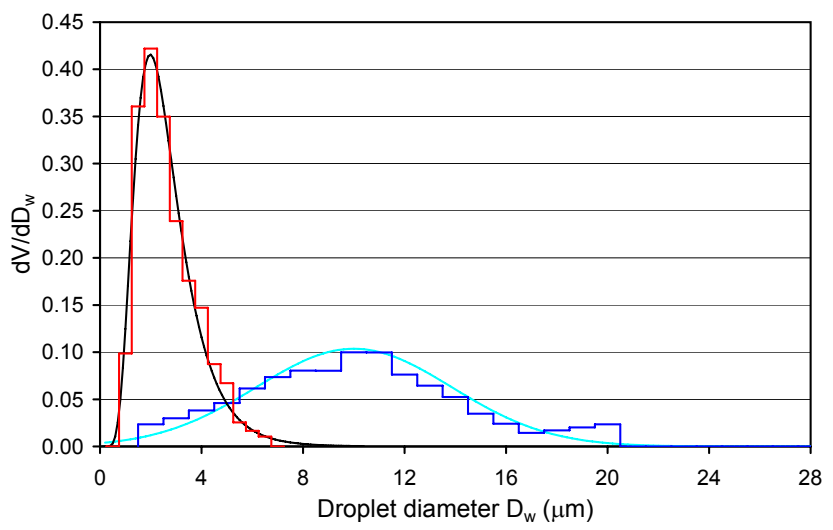

Fig. 1. Normalized volume distribution of water-in-oil emulsions: microscopically determined distributions are given in red (small droplets) and dark blue (large droplets), fitted functions in black (lognormal distribution, small droplets) and light blue (normal distribution, large droplets).

geometric standard deviation of $2.40 \mu \mathrm{m}$ and 1.55 , respectively. In the following, we will refer to the emulsions with smaller and larger water droplets as the $2.4-\mu \mathrm{m}$ and the 10$\mu \mathrm{m}$-droplet emulsions, respectively. For the heterogeneous freezing experiments in the presence of ATD only experiments with the $10-\mu \mathrm{m}$-droplet emulsion were carried out.

\subsection{Particle size distribution of ATD}

Two samples of commercially available ultra fine Arizona test dusts (ATD, Powder Technology Inc.) were used in the experiments: one with nominal $0-3 \mu \mathrm{m}$ particle diameters and one with $0-7 \mu \mathrm{m}$. In the following, we will refer to the one with $0-3 \mu \mathrm{m}$ particle diameters as fine and the one with $0-7 \mu \mathrm{m}$ as coarse ATD. According to the distributor, both products have the same chemical composition with $\mathrm{SiO}_{2}$ and $\mathrm{Al}_{2} \mathrm{O}_{3}$ as the main components. They have already been used to study heterogeneous ice nucleation by Möhler et al. (2006; fine ATD) and by Knopf and Koop (2006; coarse ATD), who also detailed the elemental composition. The size distributions were measured with a scanning mobility particle sizer (DMA Model 3081 and CPC Model 3010, TSI) and an aerodynamic particle spectrometer (APS, TSI). A bulk density of $2.6 \mathrm{~g} / \mathrm{cm}^{3}$ was used to convert the aerodynamic diameter measured with the APS into a mobility-equivalent diameter for comparison with the SMPS data. Particles were dispersed in the air by a Fluidized Bed Generator (TSI, Model 3400A) for the APS and SMPS measurements. The measured size distribution of fine ATD has been approximated by a lognormal function with a median diameter of $0.35 \mu \mathrm{m}$ and a geometric standard deviation of 1.84. For coarse ATD two superposed lognormal functions were used to fit the size distribution: $17 \%$ of one with $0.89 \mu \mathrm{m}$ median diameter and 2.2 geometric standard deviation, and $83 \%$ of one with $0.31 \mu \mathrm{m}$ median diameter and 1.73 geometric standard deviation. The

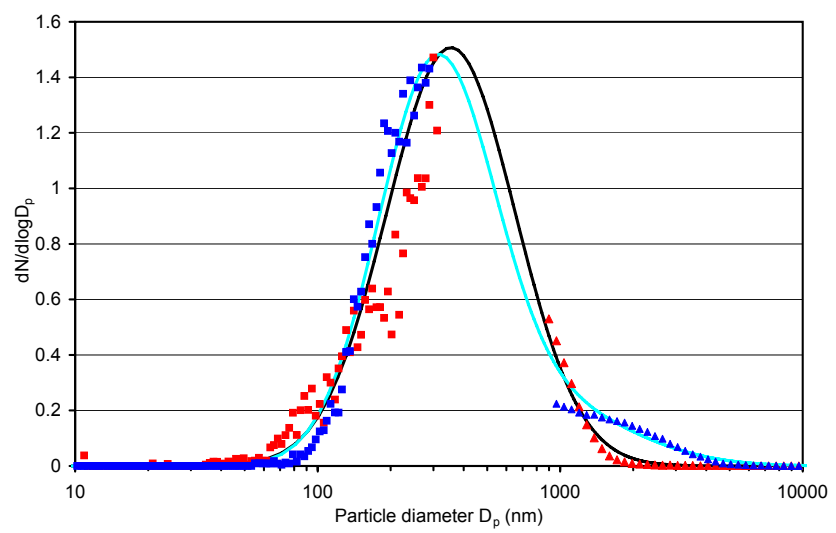

Fig. 2. Normalized number distributions of Arizona Test Dust (ATD): measured size distributions are given in red (fine ATD; squares: scanning mobility particle sizer (SMPS), triangles: aerodynamic particle spectrometer (APS)) and dark blue (coarse ATD; squares: SMPS, triangles: APS). Fitted distributions are in black (fine ATD) and light blue (coarse ATD).

measured size distributions together with the fitted ones are shown in Fig. 2.

\subsection{DSC measurements}

Emulsion droplet freezing was studied with a differential scanning calorimeter (DSC; TA Instruments Q10) in which nucleation is detected by the latent heat released during freezing. The DSC temperature calibration was performed with the melting point of ice and the ferroelectric phase transition of $\left(\mathrm{NH}_{4}\right)_{2} \mathrm{SO}_{4}$ at $223.1 \mathrm{~K}$, leading to an accuracy of the reported freezing temperatures of $\pm 0.5 \mathrm{~K}$. The precision in temperature for a single emulsion is distinctly better than $0.2 \mathrm{~K}$. In a typical DSC experiment, the first two freezing/melting cycles are run at a cooling rate of $10 \mathrm{Kmin}^{-1}$ to check the stability of the emulsions. The third freezing cycle with a cooling rate of $1 \mathrm{Kmin}^{-1}$ was used for evaluation. The slow cooling rate of this cycle allowed minimizing peak broadening due to instrumental heat flow limitations.

\section{Modeling}

\subsection{Classical Nucleation Theory}

Although far from being an accurate or ab initio description of nucleation processes, Classical Nucleation Theory (CNT) offers a suitable framework to parameterize homogeneous and heterogeneous nucleation rates as a function of temperature. It expresses the homogeneous ice nucleation rate coefficient for supercooled water, $j_{\text {hom }}(T)$ (Pruppacher and Klett, 1997), as

$j_{\text {hom }}(T)=\frac{k T}{h} \exp \left[-\frac{\Delta F_{\text {diff }}(T)}{k T}\right] \times n_{v} \exp \left[-\frac{\Delta G(T)}{k T}\right](1)$ 
where $k$ and $h$ are the Boltzmann and Planck constants, respectively, $T$ is the absolute temperature, $n_{v}$ the number density of water molecules (typically $n_{v}=3.1 \times 10^{22} \mathrm{~cm}^{-3}$ ), $\Delta F_{\text {diff }}(T)$ the diffusion activation energy of a water molecule to cross the water/ice embryo interface, and $\Delta G(T)$ the Gibbs free energy for the formation of the critical ice embryo in the absence of a heterogeneous ice nucleus. The second term in Eq. (1) (behind the times sign) describes the concentration of critical (viable) ice embryos; the first term is the diffusive flux of water molecules to the ice embryos during their nascency.

In CNT, $\Delta G(T)$ is given by (Seinfeld and Pandis, 1998):

$\Delta G(T)=\frac{16 \pi}{3} \frac{v_{\text {ice }}^{2}(T) \sigma_{s l}^{3}(T)}{[k T \ln S(T)]^{2}}$,

where $v_{\text {ice }}(T)$ is the volume of a $\mathrm{H}_{2} \mathrm{O}$ molecule in ice, $\sigma_{s l}(T)$ the interfacial tension between water and the ice embryo and $S(T)$ the ice saturation ratio defined by

$S(T)=\frac{p_{\mathrm{H}_{2} \mathrm{O}}(T)}{p_{\text {ice }}(T)}$,

where $p_{\mathrm{H}_{2} \mathrm{O}}$ and $p_{\text {ice }}$ are the vapor pressures of supercooled liquid water and ice, respectively. Most recent parameterizations for $p_{\mathrm{H}_{2} \mathrm{O}}$ and $p_{\text {ice }}$ are given by Murphy and Koop (2005). Temperature dependent parameterization of $\Delta F_{\text {diff }}(T), v_{\text {ice }}(T)$ and $\sigma_{s l}(T)$ used here are the same as in Zobrist et al. (2007).

In a generalization of homogeneous nucleation the heterogeneous ice nucleation rate coefficient has been expressed as (Pruppacher and Klett, 1997)

$$
\begin{aligned}
j_{\text {het }}(T)= & \frac{k T}{h} \exp \left[-\frac{\Delta F_{\text {diff }}(T)}{k T}\right] \\
& \times n_{s} \exp \left[-\frac{\Delta G(T) \times f_{\text {het }}}{k T}\right],
\end{aligned}
$$

where $n_{s}\left(\approx 10^{15} \mathrm{~cm}^{-2}\right)$ is the number density of water molecules at the ice nucleus/water interface and the compatibility function $f_{\text {het }}(\leq 1)$ describes the reduction of the Gibbs energy barrier due to the presence of an ice nucleus. The compatibility function may be expressed as (Seinfeld and Pandis, 1998)

$f_{\text {het }}=\frac{1}{4}(2+\cos \alpha)(1-\cos \alpha)^{2}$.

Here, $\alpha$ formally represents the contact angle between the ice embryo and the ice nucleus in an aqueous medium. The parameter $\alpha$ may assume values between 0 and $180^{\circ}$ leading to values for $f_{\text {het }}$ between 0 (perfect compatibility) and 1 (no compatibility), respectively. Equation (5) is valid for plain surfaces and does not strictly apply to curved or rough surfaces. In the following, we will use $\alpha$ as a fitting parameter and do not intend to imply a microscopic picture of ice nucleation with this.

\subsection{Modeling homogeneous emulsion freezing}

The number of droplets freezing homogeneously in an emulsion in a time interval $t$ is given by

$n_{\text {hom }}(t)=n_{l}\left(1-\exp \left(-j_{\text {hom }} V t\right)\right)$,

where $n_{l}$ is the total number of (initially liquid) droplets within a droplet size class given by volume $V$ of an individual droplet. To model the DSC signal, the temperature was decreased at a cooling rate of $1 \mathrm{Kmin}^{-1}$ and at each 1$\mathrm{s}$ time step the fraction of frozen droplets for each droplet size class was evaluated based on Eq. (6). For the 2.4- $\mu \mathrm{m}$ droplet emulsion, droplet size bins from 0.3-7.8 $\mu \mathrm{m}$ diameter with $0.3 \mu \mathrm{m}$ spacing and for the $10-\mu \mathrm{m}$-droplet emulsion, bins from 1-25 $\mu \mathrm{m}$ diameter with $1 \mu \mathrm{m}$ spacing were calculated. The latent heat released by each droplet size class was weighted by its volume fraction in the droplet volume distribution of the emulsion and then summed up.

The DSC technique monitors the differential energy required to keep both a sample and a reference at the same temperature while the average temperature is changing at a constant rate. The DSC instrument is therefore sensitive to the latent heat release due to the nucleation events. When water freezes, the time dependence of latent heat recorded by the DSC follows an exponential decay law $(\exp (-t / \tau))$ given by the involved heat capacities of the sample and the instrument itself. Therefore, the DSC still records a signal after the emulsion droplets are all frozen. For high enough cooling rates, the damping of the heat transfer may considerably broaden the freezing peak. Figure 3 shows that for a cooling rate of $1 \mathrm{Kmin}^{-1}$ the freezing curve returns to baseline values at $232 \mathrm{~K}$ and $233 \mathrm{~K}$ for the $2.4-\mu \mathrm{m}$ and $10-\mu \mathrm{m}$-droplet emulsions, respectively. When the emulsions are measured with a cooling rate of $10 \mathrm{Kmin}^{-1}$ the heat signal peaks at $232 \mathrm{~K}$ and extends almost to $222 \mathrm{~K}$. The comparison of freezing cycles run at these two different cooling rates allows to evaluate the time constant $(\tau)$ of heat transfer. Whereas in the cycle run at $1 \mathrm{Kmin}^{-1}$ nucleation is complete already above $232 \mathrm{~K}$, the curve segment just above $230 \mathrm{~K}$ in the $10 \mathrm{Kmin}^{-1}$ run is still affected by heat-induced retardation of nucleation (which we take explicitly into account), while the segment below $229 \mathrm{~K}$ is exclusively due to the instrumental time lag of heat transfer. We found that the latter follows indeed an exponential decay law and a fit to this curve segment results in a time constant for heat transfer of $\tau=11 \mathrm{~s}$.

The retention of heat in the DSC sample leads to an increase of the sample temperature. If this increase is neglected, the model evaluates the nucleation rate at a lower than the effective emulsion temperature. Emulsion heating is given by the difference between the latent heat released during freezing and the heat removed from the sample divided by the heat capacity of the emulsion. The latent heat released during water freezing depends on the freezing temperature (Speedy, 1987; Johari et al., 1994). At $0^{\circ} \mathrm{C}$ the excess enthalpy of water, $\Delta_{s}^{l} H$, is $6.008 \mathrm{kJmol}^{-1}$ while at 
$-40^{\circ} \mathrm{C}$ it is $4.06 \mathrm{~kJ} \mathrm{~mol}^{-1}$ (Speedy, 1987). The DSC signal is therefore larger when a certain volume of water freezes at $0^{\circ} \mathrm{C}$ than when it freezes at $-40^{\circ} \mathrm{C}$. We account for this by multiplying the freezing events with the heat release at the nucleation temperature. For convenience we fitted a fourth grade polynomial to the excess enthalpy data tabulated by Speedy (1987). The heat capacity of water increases from $75.93 \mathrm{JK}^{-1} \mathrm{~mol}^{-1}$ at $0^{\circ} \mathrm{C}$ to $116.55 \mathrm{JK}^{-1} \mathrm{~mol}^{-1}$ at $-40^{\circ} \mathrm{C}$ (Speedy, 1987). The heat capacity of mineral oil, as the main component of the emulsion, is $1.966 \mathrm{Jg}^{-1} \mathrm{~K}^{-1}$ at room temperature (Godfrey and Herguth, 1995). As a general trend, the heat capacities of hydrocarbons decrease with decreasing temperature. This decrease is $\sim 30 \%$ for $\mathrm{C}_{10} \mathrm{H}_{22}-\mathrm{C}_{20} \mathrm{H}_{42}$ hydrocarbons over a temperature interval of $40 \mathrm{~K}$ (Perry and Green, 1997). The heat capacity of the emulsion should therefore be in the range of $2.0-2.5 \mathrm{JK}^{-1} \mathrm{~g}^{-1}$ and not vary strongly with temperature. In addition, the sample pan may also accommodate a part of the heat, thus increasing the effective heat capacity of the emulsion. We will therefore use the heat capacity as a fit parameter to reproduce the DSC signal in our model calculations. Furthermore, we assume instantaneous heat release upon freezing using the temperature dependent excess freezing enthalpies by Speedy (1987) and removal of heat following an exponential decay law with a time constant of $\tau=11 \mathrm{~s}$.

During a high and sudden heat release, the effective cooling rate as recorded by the DSC deviates from the nominal one. For a cooling rate of $1 \mathrm{Kmin}^{-1}$, homogeneous water freezing in an emulsion sample leads to a decrease of the effective cooling rate to $\sim 0.6 \mathrm{Kmin}^{-1}$ followed by an increase to $\sim 1.7 \mathrm{Kmin}^{-1}$ thus maintaining the nominal value of $1 \mathrm{Kmin}^{-1}$ averaged over the whole cooling ramp. In our model calculations, we will describe the observed deviation from the nominal cooling rate as being proportional to the heat flow registered by the DSC.

\subsection{Modeling heterogeneous emulsion freezing}

To model heterogeneous freezing of the investigated emulsions, the ATD surface area present in each droplet has to be known. This quantity can be determined from the ATD concentration in the emulsion and the size distribution of ATD particles if one assumes that ATD is randomly distributed between droplets. For this calculation, the size distribution of ATD was divided into 80 logarithmic spaced size bins with particle diameters from $7 \mathrm{~nm}-20 \mu \mathrm{m}$. Heterogeneous nucleation rate coefficients were determined according to Eq. (4) for ATD containing droplets while homogeneous freezing was assumed for empty droplets. For heterogeneous nucleation, the number of freezing events in an emulsion per time interval $t$ is given by

$n_{\text {het }}(t)=n_{l}\left(1-\exp \left(-j_{\text {het }} A_{d} t\right)\right)$,

where $A_{d}$ is the ATD surface present in a droplet. Droplet freezing was evaluated for the $10-\mu \mathrm{m}$-droplet emulsion for

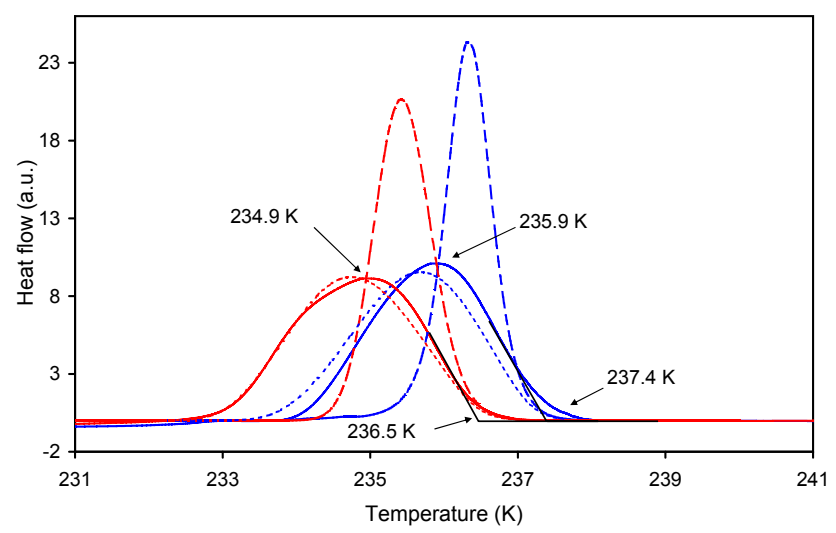

Fig. 3. Freezing experiment of water-in-oil emulsions with the 2.4$\mu \mathrm{m}$ (red) and $10-\mu \mathrm{m}$ (blue) droplet emulsions for a nominal cooling rate of $1 \mathrm{Kmin}^{-1}$. Solid lines: differential scanning calorimeter (DSC) measurements. Dashed lines: ice freezing curves modeled by Classical Nucleation Theory (CNT) assuming strictly $1 \mathrm{Kmin}^{-1}$ cooling rates. Dotted lines: ice freezing curves modeled by CNT taking internal sample heating and deviations from the nominal cooling rate into account. Black lines: the intersection of the tangent drawn at the point of greatest slope at the leading edge of the thermal peak with the interpolated baseline is used as identifier for freezing onset.

bins from $1-25 \mu \mathrm{m}$ diameter at a cooling rate of $1 \mathrm{Kmin}^{-1}$ and time steps of $1 \mathrm{~s}$. For each droplet size class the freezing events for an ensemble of 1000 droplets loaded with randomly distributed ATD particles were calculated. As above, the latent heat released by each droplet size class was weighted by its volume fraction in the droplet volume distribution of the emulsion and summed up over all size classes.

\section{Results and discussion}

\subsection{Homogeneous nucleation}

\subsubsection{Observations}

Freezing of the 2.4- $\mu \mathrm{m}$ and $10-\mu \mathrm{m}$-droplet emulsions was monitored in the DSC with a cooling rate of $1 \mathrm{Kmin}^{-1}$. The results of these experiments are presented in Fig. 3. The freezing curves of the $2.4-\mu \mathrm{m}$ and $10-\mu \mathrm{m}$-droplet emulsions show the onset of freezing at $236.5 \mathrm{~K}$ and $237.4 \mathrm{~K}$ and peak at $234.9 \mathrm{~K}$ and $235.9 \mathrm{~K}$, respectively. The observed freezing temperatures are in good agreement with recent literature data: Krämer et al. (1999) measured freezing temperatures between 236 and $237 \mathrm{~K}$ for water droplets in the 10 $70 \mu \mathrm{m}$ diameter range in an electrodynamic balance. In the AIDA chamber, Benz et al. (2005) observed homogeneous freezing of cloud droplets with $\sim 6 \mu \mathrm{m}$ diameters in the temperature range between 236 and $237.5 \mathrm{~K}$. This good agreement suggests that nucleation rates of water-in-oil emulsions and of contact-free water droplets stem from the same 

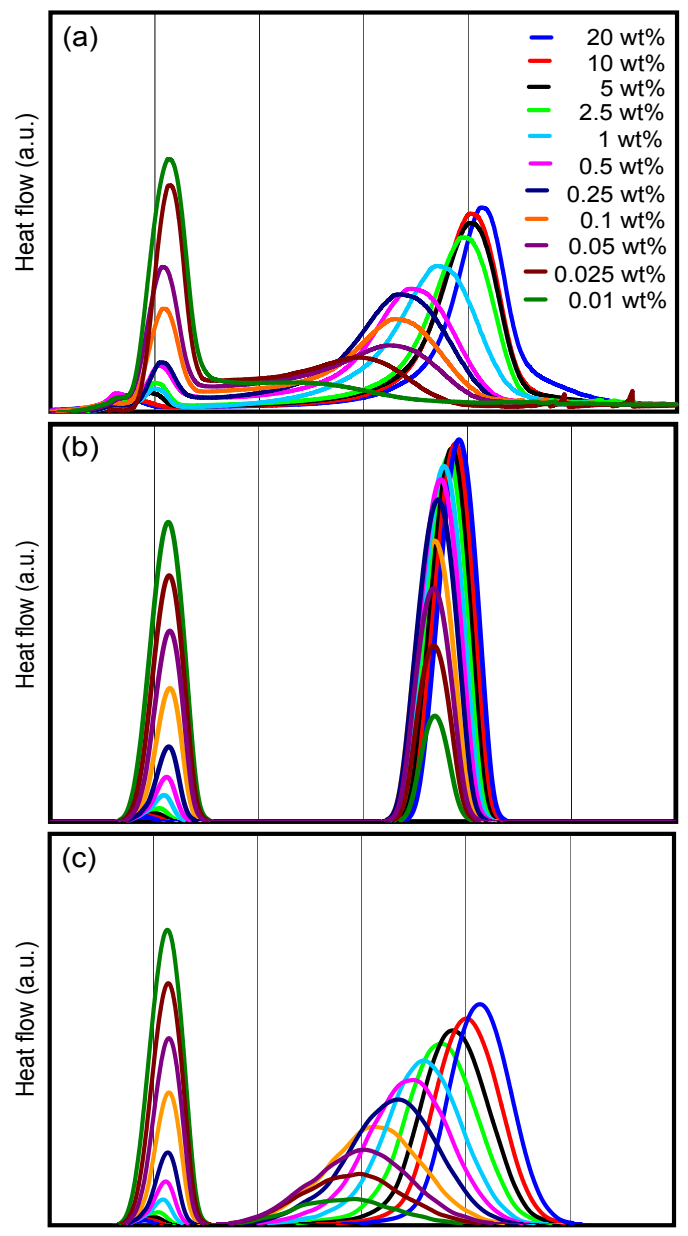

(d)

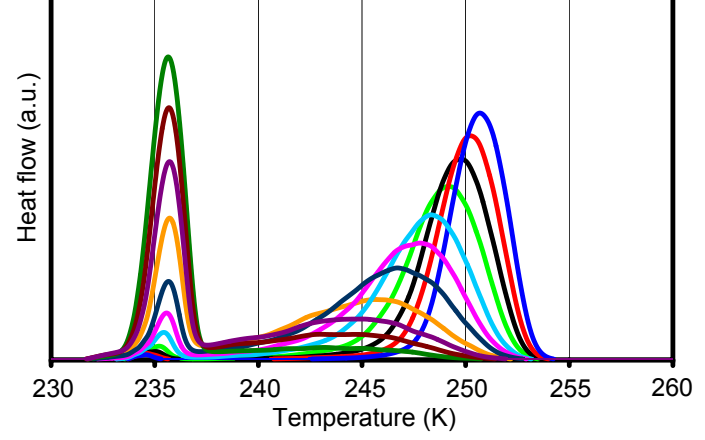

Fig. 4. Ice nucleation of fine ATD. (a) DSC thermograms of freezing experiments with nominal cooling rate of $1 \mathrm{Kmin}^{-1}$ of emulsified aqueous suspensions of fine ATD with concentrations from 0.01-20 wt \%. Right group of freezing peaks: heterogeneous nucleation; left peaks: remaining homogeneous nucleation. (b) Modeled thermograms including heat-release-induced deviations from the nominal cooling rate and assuming a constant contact angle of $65^{\circ}$. (c) Modeled thermograms as in (b), but assuming a lognormal size distribution of contact angles. (d) Modeled thermograms as in (b), but assuming nucleation occurring on active sites. nucleation mechanism, namely formation of critical embryos in the bulk of the water, and are likely not affected by the surfactant/droplet or vapor/droplet interfaces. Our results are also in agreement with an older DSC study performed with water-in-oil emulsions with mean droplet diameters of $3 \mu \mathrm{m}$ and an observed freezing range from $232.65-235.65 \mathrm{~K}$ with the most probable freezing temperature at $234.15 \mathrm{~K}$ (Broto and Clausse, 1976). Furthermore, the Figure indicates that an increase of the mean droplet volume by a factor of $(10 / 2.4)^{3}=72$ resulted in an increase of the ice nucleation temperature by $\sim 1 \mathrm{~K}$, i.e. a slope $d \log _{10}\left(j_{\text {hom }}\right) / d T \approx-1.8$, which is in reasonable agreement with the slope $-1.5( \pm 0.7)$ given by Koop et al. (2000).

\subsubsection{Modeling}

The dashed and dotted lines in Fig. 3 show the modeled DSC signals. The dashed lines were calculated based on the experimentally determined size distributions, a constant cooling rate of $1 \mathrm{Kmin}^{-1}$, nucleation rates parameterized with CNT and temperature dependent freezing enthalpy that is immediately released upon nucleation. Conversely, the dotted lines take sample heating caused by heat transfer limitation and deviation of the effective cooling rate from the nominal one into account. The dashed curves have their onsets at 236.3 and $237.1 \mathrm{~K}$ and peak at 235.4 and $236.3 \mathrm{~K}$ for the $2.4-\mu \mathrm{m}$ and $10-\mu \mathrm{m}$-droplet emulsions, respectively. Compared with the measured freezing peak, they are somewhat shifted to higher temperatures and by about a factor two too narrow. When sample heating and the deviation from the nominal cooling rate are taken into account, the modeled DSC signals considerably broaden and their maxima shift to 234.7 and $235.6 \mathrm{~K}$ for the $2.4-\mu \mathrm{m}$ and $10-\mu \mathrm{m}$-droplet emulsions, respectively (dotted lines). This closely reproduces the measured curves. For this calculation, the increase of the emulsion temperature caused by heat transfer limitation was determined as the difference between the latent heat released during water freezing and the heat removed from the sample divided by the heat capacity of the emulsion. The heat release was described by a parameterization of experimental data (Speedy, 1987), and the heat removal by an exponential decay law with a time constant $\tau=11 \mathrm{~s}$ (see Sect. 3.2). Optimization of the heat capacity to reproduce the DSC signal yielded a value of $2.75 \mathrm{JK}^{-1} \mathrm{~g}^{-1}$. This value is $0.25-$ $0.75 \mathrm{JK}^{-1} \mathrm{~g}^{-1}$ higher than estimates based on the heat capacities of water and mineral oil as the main components of the emulsion, indicating that the aluminum pan also contributes to the heat capacity of the sample. With this formulation, the emulsion temperature raises up to $1.5 \mathrm{~K}$ above the nominal value thus temporarily reducing the nucleation rate by up to three orders of magnitude.

The effective cooling rate measured by the DSC was modeled by adding a term to the nominal cooling rate that is proportional to the calculated heat signal. Optimization of the proportionality factor yielded satisfactory agreement 
between measured and modeled effective cooling rates. The close reproduction of the freezing curves shown in Fig. 3 demonstrates that the DSC signal of emulsion freezing can be well described by CNT when sample heating and the deviation from the nominal cooling rate are taken into account.

\subsection{Heterogeneous ice nucleation with ATD}

\subsubsection{Observations}

Heterogeneous ice nucleation was investigated for fine $(0$ $3 \mu \mathrm{m}$ diameter) and coarse ( $0-7 \mu \mathrm{m}$ diameter) ATD. Figs. $4 \mathrm{a}$ and 5a show the freezing of emulsified suspensions with ATD contents of the aqueous phase from $0.01-20 \mathrm{wt} \%$ and $1-20 \mathrm{wt} \%$ for fine and coarse ATD, respectively. The presence of ATD in the emulsions leads to a second DSC peak caused by heterogeneous ice nucleation on the ATD surface at higher temperature than that of homogeneous ice nucleation. From this, we conclude that mineral dust partitions to the water droplets and is not covered by the surfactant. To our knowledge, interactions of lanolin or substances consisting of the same functional groups as lanolin with montmorillonite or kaolinite - main components of mineral dusts have not been reported in the literature. Nevertheless, minor adsorption of lanolin to the ATD surface can not be excluded on the basis of the available evidence.

It can be seen from Figs. $4 \mathrm{a}$ and $5 \mathrm{a}$ that the heterogeneous freezing peaks are generally broader than the homogeneous ones, and they broaden further when the number of ATD particles per water droplet decreases. For the lowest concentrations, heterogeneous freezing extends all the way to the onset of homogeneous freezing (e.g. cyan line in Fig. 5a). The freezing peak maxima of the $1,2.5,5,10$, and $20 \mathrm{wt} \%$ suspensions are at 248.5, 249.7, 250.1, 250.2, and $250.6 \mathrm{~K}$ for fine ATD compared to 245.1, 245.6, 246.8, 248.0, and $249.5 \mathrm{~K}$ for coarse ATD. Moreover, for the same weight percent of ATD, the freezing curves of coarse ATD are broader than for fine ATD. For the $20 \mathrm{wt} \%$ suspensions, the onset of the freezing peak is for fine and coarse ATD at $252.8 \mathrm{~K}$ with a weak tail extending up to $256 \mathrm{~K}$. Knopf and Koop (2006) observed water droplet formation followed by freezing at $260 \mathrm{~K}$ when coarse ATD deposited on a hydrophobic substrate was exposed to supersaturated water vapor. This is distinctly above the onset of freezing in our DSC experiment and indicates that for this IN condensation freezing might be more efficient than immersion freezing.

For the highest ATD content almost only heterogeneous freezing occurs while emulsions with low ATD content predominantly freeze homogeneously, since the occurrence of at least one ATD particle is a prerequisite for heterogeneous ice nucleation in an emulsion droplet. Whether this is the case strongly depends on the droplet size and the ATD suspension concentration. Assuming that the ATD particles are randomly distributed in the emulsion droplets, the average
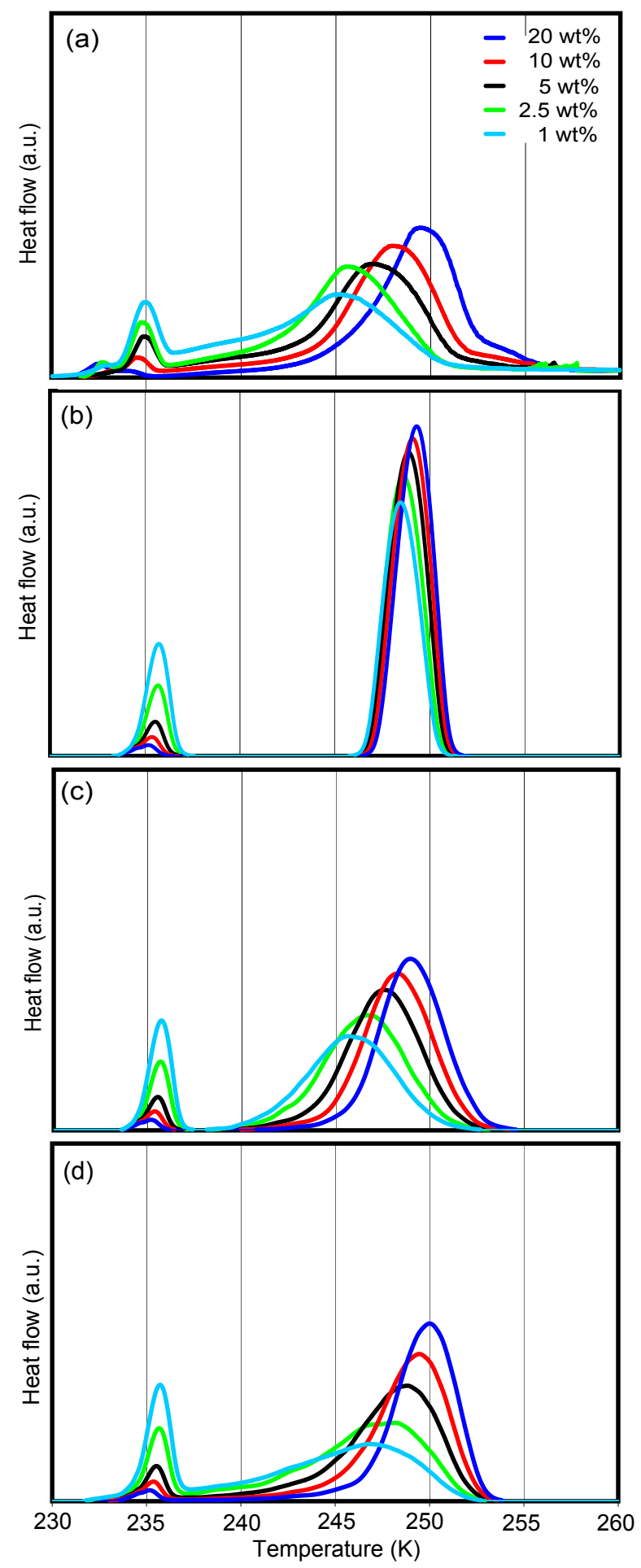

Fig. 5. Ice nucleation of coarse ATD. (a) DSC freezing experiment of emulsified aqueous suspensions of coarse ATD with concentrations from 1-20 wt\%. (b) Modeled freezing curve with a constant contact angle of $65^{\circ}$. (c) Modeled freezing curve with a lognormal size distribution of contact angles. (d) Modeled freezing curve with nucleation occurring on active sites. 
droplet occupancy can be calculated. In the case of a fine ATD concentration of $0.01 \mathrm{wt} \%$, droplets with diameters up to $16 \mu \mathrm{m}$ are predominantly empty, only $17 \%$ of the $10 \mu \mathrm{m}$ droplets contain an ATD particle and the prevailing number of droplets is only filled with 1 ATD particle. For the most concentrated emulsion with $20 \mathrm{wt} \%$ fine ATD, only the smallest droplets with diameters lower than $2 \mu \mathrm{m}$ are predominantly empty. 5- $\mu \mathrm{m}$-droplets are on average filled with $60,10-\mu \mathrm{m}$-droplets with 480 , and $15-\mu \mathrm{m}$-droplets with 1630 ATD particles. Given the same mass fraction the average occupancy of water droplets is lower for the coarse ATD than for the fine one. For $1 \mathrm{wt} \%$ ATD suspensions, droplets are predominantly empty for diameters up to $6 \mu \mathrm{m}$ and $3 \mu \mathrm{m}$ for coarse and fine ATD, respectively.

\subsubsection{Stochastic hypothesis}

In Figs. $4 b$ and $5 b$ the modeled freezing curves are shown. These calculations were carried out taking internal sample heating and limited heat conductivity into account. Assuming that the ATD particles are randomly distributed in emulsion droplets and that all particles have an equal efficiency to nucleate ice, a contact angle of $65^{\circ}$ reproduced the measured freezing temperatures best. A change of the contact angle by $10^{\circ}$ results in a shift of the freezing peak position by $\sim 5 \mathrm{~K}$. Note, that changes of contact angle hardly affect the width of the freezing curves. The modeled curves represent the ratio between homogeneous to heterogeneous freezing reasonably well, thus confirming the ATD particle size and emulsion droplet volume distributions as well as the assumption of random distribution of ATD between the droplets. The modeled heterogeneous freezing curves shift to slightly higher temperatures with increasing ATD content owing to the increase in heterogeneous surface. The calculated freezing peak maxima of fine ATD are $0.3 \mathrm{~K}$ higher than for coarse ATD, because of the larger surface present in the fine ATD for the same ATD mass fraction. While the widths of the measured homogeneous freezing curves are well represented by the model, the calculated heterogeneous freezing curves for low ATD contents are much narrower than the measured ones. Under the stochastic hypothesis with the same contact angle for all particles, the decrease of heterogeneous surface with decreasing ATD content alone is clearly not able to explain the strong shift to lower freezing temperatures and the concomitant broadening of the freezing curves.

\subsubsection{Singular hypothesis: contact angle distribution}

Given the above, we are forced to assume that the ability to nucleate ice differs between ATD particles. The contact angle, a proxy for the IN ability of a dust particle, was therefore allowed to vary between particles, while each individual dust particle was assumed to be characterized by only one contact angle. To describe the occurrence probability of contact angles, several probability functions were tested including lin- ear, quadratic, cubic, box, triangle, exponential, normal and lognormal ones. Each ATD particle was assigned stochastically a contact angle weighted with the occurrence probability function. A water droplet containing several ATD particles will now preferentially nucleate ice on the particle with the highest IN activity, i.e. the lowest contact angle. The occurrence probability function was optimized so that the modeled DSC curves match the measured ones best. Among the investigated functions, lognormal and normal distributions were found to yield similarly good agreement while other functions generated DSC curves that were in clear discrepancy with measurements. Figures $4 c$ and $5 c$ show the modeled freezing curves for a lognormal distribution with a median contact angle of $76^{\circ}$ and a geometric standard deviation of 1.083. This model is indeed capable of describing the strong broadening of the freezing curve with decreasing ATD content: for low ATD concentrations, the wide range of diverse IN qualities of the few particles present in an emulsion droplet produces a broad freezing curve, while for high concentrations the range of IN present in the droplets evens out. To some extent, this model is also able to explain the broader freezing peaks of coarse compared to fine ATD, although no particle size dependence of the contact angle is parameterized. However, at high ATD loadings, it overestimates freezing peak differences between fine ATD concentrations, while it underestimates the ones between coarse ATD concentrations. Moreover, it is not able to reproduce the tail of the freezing curve extending to the onset of homogeneous nucleation. Nevertheless, the main features of the freezing curves of fine and coarse ATD can be described by the same model parameters, indicating that the observed differences in freezing temperatures are a consequence of the size distribution rather than differences in IN quality between coarse and fine ATD surfaces.

\subsubsection{Singular hypothesis: active site distribution}

Since the assumption of contact angles varying between particles and being constant for the whole surface of a particle might not be realistic for a material like ATD, we performed a third calculation assuming that ice nucleation occurs on active sites with varying IN quality (Fletcher, 1969; Han et al., 2002). An active site area of $A_{a s}=10 \mathrm{~nm}^{2}$ was employed for all active sites. According to CNT this area corresponds to that covered by a critical embryo at $244 \mathrm{~K}$. (We used this value at all temperatures although the critical radius varies from $1.2-3.1 \mathrm{~nm}$ in the temperature range from $235-255 \mathrm{~K}$.) It was assumed that active sites with different ice nucleation abilities may be present on each individual ATD particle. Again we use a contact angle $\alpha$ as proxy for the nucleation ability of an active site. The occurrence probability $\left(P_{a s}\right)$ of an active site depends then on its contact angle, i.e. $P_{a s}(\alpha)$. By means of this probability function, the active area of each particle can be calculated in the following way: for $A_{a s}<A_{p} \times P_{a s}(\alpha)$, the particle's active area 
with a certain $\alpha$ is calculated as $A_{p} \times P_{a s}(\alpha)$, where $A_{p}$ is the particle's surface area. For $A_{a s}>A_{p} \times P_{a s}(\alpha)$, an active site is assigned to the particle, if for a randomly chosen number $n_{r} \in[0,1]$ the condition $n_{r} \times A_{a s}<A_{p} \times P_{a s}(\alpha)$ is fulfilled; otherwise the particle is assumed not to act as IN with contact angle $\alpha$. The contact angles are inserted into Eq. (5) and the active site areas are inserted into Eq. (7) to calculate the nucleation rates.

It was found that the observed freezing curves are reproduced best when the occurrence probability of active sites is low and decreases strongly with decreasing contact angle. Figures $4 \mathrm{~d}$ and $5 \mathrm{~d}$ show the resulting DSC curves for the occurrence probability function that matched the measurements best:

$$
P_{a s}(\alpha)=10^{-5} \exp \left(-51^{\circ} /\left(\alpha-46^{\circ}\right)\right)
$$

This function is shown in Fig. 6. It resulted from a selection process which involved the test of different functions and the variation of their fitting parameters but can not be considered as a unique solution. According to this probability function, only a minor part of the ATD surface acts as IN: a surface fraction of $8.2 \times 10^{-7}$ exhibits contact angles of $60^{\circ}$ or better, a fraction of $8.3 \times 10^{-6}$ contact angles of $70^{\circ}$ or better, and a fraction of $1.3 \times 10^{-4}$ contact angles of $110^{\circ}$ or better. This means that particles with diameters of $0.16 \mu \mathrm{m}$ have on average one active site of $110^{\circ}$ or better, while only particles with diameters of 0.62 and $2.0 \mu \mathrm{m}$ contain on average an active site of at least $70^{\circ}$ and $60^{\circ}$, respectively. In contrast to the assumption of a contact angle distribution, larger particles are now on average better IN than smaller ones because they contain more and also better active sites. The low number of active sites provides ATD particles with the wide range of IN activities that is needed to reproduce the large spread of freezing temperatures observed for ATD suspensions with low concentrations. The active site model is therefore able to reproduce the strong broadening of the freezing curve with decreasing ATD content including the tail extending to the onset of homogeneous nucleation. It shows a very good agreement for fine ATD. It also describes the peak broadening of coarse ATD but underestimates the shift of peak maxima to lower temperatures with decreasing ATD content.

Neither the contact angle nor the active site distribution fully explain the tail to higher freezing temperatures that is visible especially in the measurements of the $20 \mathrm{wt} \%$ suspensions. However, we did not try to further improve these models because these discrepancies might also be due to inaccuracies in droplet volume and ATD size distributions.

\section{Conclusions}

DSC freezing experiments with emulsified aqueous suspensions of ATD showed that this mineral dust acts as immersion

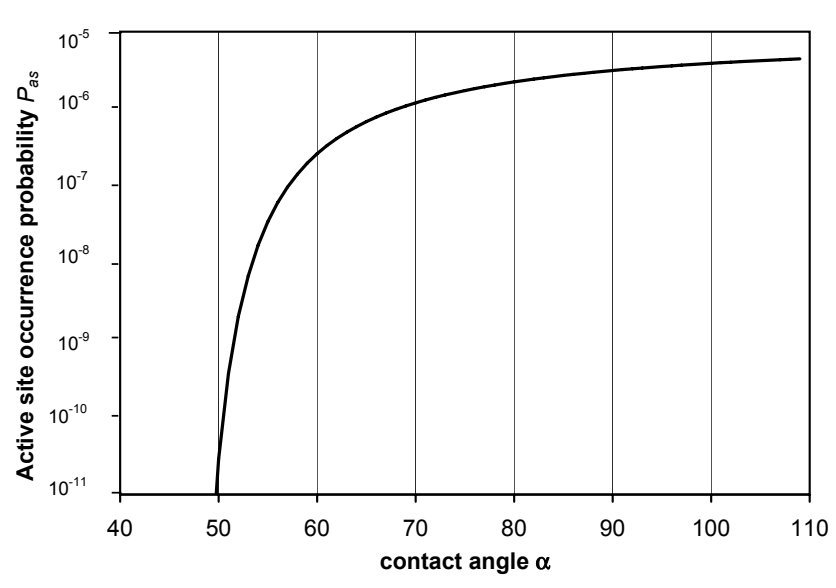

Fig. 6. Occurrence probability of active sites as a function of contact angle $\alpha$. This function was used to calculate the freezing curves in Figs. $4 d$ and $5 d$.

mode IN. The measured DSC thermograms exhibit a homogeneous and a heterogeneous freezing peak whose intensity ratios vary with the concentration of ATD in the aqueous suspension, such that larger ATD concentrations lead to a larger heterogeneous peak. Heterogeneous ice nucleation strongly depends on ATD concentration with freezing temperatures up to $256 \mathrm{~K}$ and down to the onset of homogeneous ice nucleation.

To model the DSC freezing curves with CNT, the ATD size and water droplet volume distributions were determined. The intensity ratio of the homogeneous to the heterogeneous freezing peaks is consistent with the assumption of random distribution of ATD within the emulsion droplets. Excellent agreement with the measured homogeneous freezing curves is obtained when sample heating and the deviation from the nominal cooling rate due to latent heat release during freezing are taken into account. In addition, the strong dependence of heterogeneous freezing temperatures on the ATD concentration in the suspension can only be modeled by using a distribution of contact angles instead of one constant value, indicating that not all ATD particles are equal IN and reinforcing the singular hypothesis. The measured DSC curves are in good agreement with the assumption that the ability of ATD particles to nucleate ice is (log)normally distributed with some particles being very good and others being poor IN. Such distributions can be realized when ice nucleation occurs on few active sites of varying quality instead of the whole ATD surface. If the occurrence probability of active sites is a function of surface area, the number and quality of active sites on a particle increases with particle size, making larger particles better IN than smaller ones, although the ATD surface of all particles can be described by the same nucleation parameters. The active site model that yielded best agreement with the measured DSC curves implies that only a very minor fraction of the ATD surface is indeed effective 
as IN. This result is in accordance with a study performed by Anderson and Hallett (1976) who observed that ice nucleation occurred on preferred sites on $\mathrm{AgI}$ and $\mathrm{CuS}$ single crystals. They also noted that each site required a critical supersaturation for ice crystals to grow.

The considerable variation in IN quality between ATD particles implies that reported activation temperatures strongly depend on the fraction of frozen droplets defining freezing and on the number of IN involved in a freezing event. In the atmosphere, where only a fraction of the water droplets contains one or few IN, the flat freezing curves obtained for the lowest ATD concentrations might be more realistic than heterogeneous nucleation bursts similar to the homogeneous one. Parameterization within CNT offers the possibility to characterize an IN such as ATD by an occurrence probability function of contact angles that can be used to predict freezing for other suspension concentrations or in the case of the active site model, also other ATD size distributions. In this study, we applied the active site parameterization to two quite similar size distributions and therefore could not provide a rigorous test for the postulated size dependence. For a stricter validation, freezing experiments of size-selected ATD samples are needed. Increasing IN efficiency with larger particle sizes have been observed by Archuleta et al. (2005) for ice nucleation on oxide and silicate particles.

A large IN activity range is in agreement with a recent study of ice nucleation on ATD particles in the deposition mode by Knopf and Koop (2006), who observed nucleation occurring over a broad relative humidity range. On the other hand, Möhler et al. (2006) showed that significant number fractions of ATD particles are active deposition IN at very low ice supersaturations and that this fraction increases exponentially with decreasing temperature. Assuming an exponential increase of active IN with increasing contact angle leads to modeled freezing curves that are in clear contrast to the DSC signals that we observed for ice nucleation in the immersion mode. However, this discrepancy might be due to different nucleation modes and temperatures in the two studies. It highlights the importance of a detailed characterization of the parameters involved in heterogeneous ice nucleation. We therefore think that further experiments and theoretical descriptions are needed to address the full activity range of these IN.

Acknowledgements. We are grateful for support by the Swiss National Fund in various projects and by the European Commission through the integrated project SCOUT-O3.

Edited by: M. Ammann

\section{References}

Archuleta, C. M., DeMott, P. J., and Kreidenweis, S. M.: Ice nucleation by surrogates for atmospheric mineral dust and mineral dust/sulfate particles at cirrus temperatures, Atmos. Chem. Phys.,
5, 2617-2634, 2005,

http://www.atmos-chem-phys.net/5/2617/2005/.

Baker, M. B.: Cloud microphysics and climate, Science, 276, 10721078, 1997.

Benz, S., Megahed, K., Möhler, O., Saathoff, H., Wagner, R., and Schurath, U.: T-dependent rate measurements of homogeneous ice nucleation in cloud droplets using a large atmospheric simulation chamber, J. Photoch. Photobio. A, 176, 208-217, 2005.

Bertram, A. K., Koop, T., Molina, L. T., and Molina, M. J.: Ice formation in $\left(\mathrm{NH}_{4}\right)_{2} \mathrm{SO}_{4}-\mathrm{H}_{2} \mathrm{O}$ particles, J. Phys. Chem. A, 104, 584-588, 2000.

Broto, F. and Clausse, D.: A study of the freezing of supercooled water dispersed within emulsions by differential scanning calorimetry, J. Phys. C Solid State, 9, 4251-4257, 1976.

Clausse, D., Bouabdillah, D., Cochet, N., Luquet M. P., and Pulvin, S.: Ice crystallization induced by silver iodide and bacteria in microsize droplets dispersed within emulsions, Pure Appl. Chem., 63, 1491-1494, 1991.

Clausse, D., Gomez, F., Pezron, I., Komunjer, L., and Dalmazzone, C.: Morphology characterization of emulsions by differential scanning calorimetry, Adv. Colloid Interfac., 117, 59-74, 2005.

Cotton, W. R., Tripoli, G. J., Rauber, R. M., and Mulvihill E. A.: Numerical simulation of the effects of varying ice crystal nucleation rates and aggregation processes on orographic snowfall, J. Clim. Appl. Meteorol., 25, 1658-1680, 1986.

DeMott, P. J., Cziczo, D. J., Prenni, A. J., Murphy, D. M., Kreidenweis, S. M., Thomson, D. S., Borys, R., and Rogers, D. C.: Measurements of the concentration and composition of nuclei for cirrus formation, P. Natl. Acad. Sci. USA, 100, 14 655-14 660, 2003a.

DeMott, P. J., Sassen, K., Poellot, M. R., Baumgardner, D., Rogers, D. C., Brooks, S. D., Prenni, A. J., and Kreidenweis S. M.: African dust aerosols as atmospheric ice nuclei, Geophys. Res. Lett., 30(14), 1732, doi:10.1029/2003GL017410, 2003b.

Diehl, K. and Wurzler, S.: Heterogeneous drop freezing in the immersion mode: Model calculations considering soluble and insoluble particles in the drops, J. Atmos. Sci., 61, 2063-2072, 2004.

Fletcher, N. H.: Active sites and ice crystal nucleation, J. Atmos. Sci., 26, 1266-1271, 1969.

Godfrey, D. and Herguth, W. R.: Physical and chemical properties of industrial mineral oils affecting lubrication, Part 2, Lubr. Eng., 51, 493-496, 1995.

Han, J. H., Hung, H. M., and Martin, S. T.: Size effect of hematite and corundum inclusions on the efflorescence relative humidities of aqueous ammonium nitrate particles, J. Geophys. Res., 107(D10), 4086, doi:10.1029/2001JD001054, 2002.

Hobbs, P. V. and Rangno, A. L.: Ice particle concentrations in clouds, J. Atmos. Sci., 42, 2523-2549, 1985.

Hung, H. M., Malinowski, A., and Martin, S. T.: Kinetics of heterogeneous ice nucleation on the surfaces of mineral dust cores inserted into aqueous ammonium sulfate particles, J. Phys. Chem. A, 107, 1296-1306, 2003.

Johari, G. P., Fleissner, G., Hallbrucker, A., and Mayer, E.: Thermodynamic continuity between glassy and normal water, J. Phys. Chem., 98, 4719-4725, 1994.

Knopf, D. A. and Koop, T.: Heterogeneous nucleation of ice on surrogates of mineral dust, J. Geophys. Res., 111, D12201, 
doi:10.1029/2005JD006894, 2006.

Koop, T., Bertram, A. K., Molina, L. T., and Molina, M. J.: Phase transitions in aqueous $\mathrm{NH}_{4} \mathrm{HSO}_{4}$ solutions, J. Phys. Chem. A, 103, 9042-9048, 1999.

Koop, T., Luo, B. P., Tsias, A., and Peter, T.: Water activity as the determinant for homogeneous ice nucleation in aqueous solutions, Nature, 406, 611-614, 2000.

Krämer, B., Hübner, O., Vortisch, H., Wöste, L., Leisner, T., Schwell, M., Rühl, E., and Baumgärtel, H.: Homogeneous nucleation rates of supercooled water measured in single levitated microdroplets, J. Chem. Phys., 111, 6521-6527, 1999.

Krueger, B. J., Grassian, V. H., Cowin, J. P., and Laskin, A.: Erratum to "Heterogeneous chemistry of individual mineral dust particles from different dust source regions: The importance of particle mineralogy", Atmos. Environ., 39, p. 395, 2005.

Kumai, M.: Snow crystals and the identification of the nuclei in the northern United States of America, J. Meteorol., 18, 139-150, 1961.

Kumai, M. and Francis, K. E.: Nuclei in snow and ice crystals on the Greenland Ice Cap under natural and artificially stimulated conditions, J. Atmos. Sci., 19, 474-481, 1962.

Lohmann, U. and Diehl, K.: Sensitivity studies of the importance of dust ice nuclei for the indirect aerosol effect on stratiform mixedphase clouds, J. Atmos. Sci., 63, 968-982, 2006.

Martin, S. T.: Phase transitions of aqueous atmospheric particles, Chem. Rev., 100, 3403-3453, 2000.

Meyers, M. P., DeMott, P. J., and Cotton, W. R.: New primary icenucleation parameterizations in an explicit cloud model, J. Appl. Meteorol., 31, 708-721, 1992.

Möhler, O., Field, P. R., Connolly, P., Benz, S., Saathoff, H., Schnaiter, M., Wagner, R., Cotton, R., Krämer, M., Mangold, A., and Heymsfield, A. J.: Efficiency of the deposition mode ice nucleation on mineral dust particles, Atmos. Chem. Phys., 6, 3007-3021, 2006,

http://www.atmos-chem-phys.net/6/3007/2006/.

Murphy, D. M. and Koop, T.: Review of the vapour pressures of ice and supercooled water for atmospheric applications, Q. J. Roy. Meteor. Soc., 131, 1539-1565, 2005.

Perry, R. H. and Green, D. W. (Eds.): Perry's chemical engineers' handbook, 7th ed., McGraw-Hill, New York, 2-94-2-98, 1997.
Pitter, R. L. and Pruppacher, H. R.: A wind tunnel investigation of freezing of small water drops falling at terminal velocity in air, Q. J. Roy. Meteor. Soc., 99, 540-550, 1973.

Pruppacher, H. R. and Klett, J. D.: Microphysics of clouds and precipitation, Kluwer, Dordrecht, 191-209 and 309-355, 1997.

Rasmussen, D. H. and MacKenzie, A. P.: Effect of solute on icesolution interfacial free energy; calculation from measured homogeneous nucleation temperatures, in: Water structure at the water polymer interface, edited by: Jellinek, H. H. G., Plenum Press, New York, 126-145, 1972.

Sassen, K., DeMott, P. J., Prospero, J. M., and Poellot, M. R.: Saharan dust storms and indirect aerosol effects on clouds: CRYSTAL-FACE results, Geophys. Res. Lett., 30(12), 1633, doi:10.1029/2003GL017371, 2003.

Seinfeld, J. H. and Pandis, S. N.: Atmospheric Chemistry and Physics, Wiley, New York, 545-595, 1998.

Speedy, R. J.: Thermodynamic properties of supercooled water at 1 atm, J. Phys. Chem., 91, 3354-3358, 1987.

Vali, G.: Freezing rate due to heterogeneous nucleation, J. Atmos. Sci., 51, 1843-1856, 1994.

Zobrist, B., Weers, U., and Koop, T.: Ice nucleation in aqueous solutions of poly[ethylene glycol] with different molar mass, J. Chem. Phys., 118, 10254-10 261, 2003.

Zobrist, B., Marcolli, C., Koop, T., Luo, B. P., Murphy, D. M., Lohmann, U., Zardini, A. A., Krieger, U. K., Corti, T., Cziczo, D. J., Fueglistaler, S., Hudson, P. K., Thomson, D. S., and Peter, T.: Oxalic acid as a heterogeneous ice nucleus in the upper troposphere and its indirect aerosol effect, Atmos. Chem. Phys., 6, 3115-3129, 2006, http://www.atmos-chem-phys.net/6/3115/2006/.

Zobrist, B., Koop, T., Luo, B. P., Marcolli, C., and Peter, T.: Heterogeneous ice nucleation rate coefficient of water droplets coated by a nonadecanol monolayer, J. Phys. Chem. C, 111, 2149-2155, 2007.

Zuberi, B., Bertram, A. K., Koop, T., Molina, L. T., and Molina, M. J.: Heterogeneous freezing of aqueous particles induced by crystallized $\left(\mathrm{NH}_{4}\right)_{2} \mathrm{SO}_{4}$, ice, and letovicite, J. Phys. Chem. A, 105, 6458-6464, 2001. 